\title{
Development of 12 microsatellite markers in Euptelea polyandra by a random tailed genome-walking method using Phi29 DNA polymerase
}

\author{
Bingyun Wu · Hiroyuki Kurokochi • \\ Taizo Hogetsu
}

Received: 31 March 2009/Accepted: 1 April 2009/Published online: 19 May 2009

(C) Springer Science+Business Media B.V. 2009

\begin{abstract}
Twelve microsatellite (simple sequence repeat, SSR) markers were isolated from Euptelea polyandra, a Japanese endemic deciduous tree species, based on a random tailed genome-walking method using Phi29 DNA polymerase. There were 2 to 11 alleles per locus, and the observed and expected heterozygosities ranged from 0.05 to 0.90 and from 0.233 to 0.883 , respectively.
\end{abstract}

Keywords Microsatellite (SSR) - Euptelea polyandra . Random tailed genome-walking · Phi29 DNA polymerase

Euptelea polyandra Sieb. et Zucc. (Eupteleaceae) is a Japanese endemic riparian tree species. For analysis of its population genetics, we first isolated microsatellite (simple sequence repeat, SSR) markers from this species based on a random tailed genome-walking method using Phi29 DNA polymerase (Reddy et al. 2008).

DNA was extracted from leaves of E. polyandra using the CTAB method (Zhou et al. 1999). Approximately $12.4 \mathrm{ng}$ of the genomic DNA was mixed with $1-\mu 110 \times$ reaction buffer, $0.05 \mathrm{mM}$ of each dNTP, and 1 pmol of a random tailed primer Ad1, Ad2, Ad3 or Ad4 (Table 1) in a tube.

B. Wu $(\varangle) \cdot$ H. Kurokochi $\cdot$ T. Hogetsu Department of Forest Science, Graduate School of Agricultural and Life Sciences, The University of Tokyo, Yayoi 1-1-1, Bunkyo-ku, Tokyo 113-8657, Japan

e-mail: bingyun@fr.a.u-tokyo.ac.jp
After DNA was heat-denatured at $94^{\circ} \mathrm{C}$ for $5 \mathrm{~min}$ and annealed to the primer at $30^{\circ} \mathrm{C}$ for 5 min, 5 units of Phi29 DNA polymerase (Epicentre Biotechnologies, USA) was added as the final volume of the reaction mixture became $10-\mu \mathrm{l}$. The mixture was incubated at $30^{\circ} \mathrm{C}$ for $1.5 \mathrm{~h}$ for multiple primer extension, and then at $65^{\circ} \mathrm{C}$ for $10 \mathrm{~min}$ for reaction termination. The products were refined with a molecular filter (SUPREC ${ }^{\mathrm{TM}}$ PCR, TaKaRa, Japan), resuspended in 20- $\mu \mathrm{l}$ of TE buffer, and used in the following genome-walking.

The first-step walking was carried out by PCR with $0.4 \mu \mathrm{M}$ of a tail primer Ad-P1 (Table 1), and $0.4 \mu \mathrm{M}$ of an SSR primer $\left((\mathrm{AC})_{10},(\mathrm{CT})_{10}\right.$ or $\left.(\mathrm{AG})_{6}(\mathrm{AC})_{5}\right)$ in a $10-\mu 1$ reaction solution using a BioTaq $^{\mathrm{TM}}$ PCR kit (Bioline, USA), amplifying $3^{\prime}$ regions flanking to the SSRs in the genome. The PCR products were integrated into plasmid Novagen pT7 Blue T-Vector (Novagen) using a TaKaRa ligation kit (version 2.1, TaKaRa). The plasmids were transformed into competent Escherichia coli (JM 109, TaKaRa), according to the manufacturer's instructions. The cloned fragments were amplified from the plasmid DNA of positive clones using the M13 forward and reverse primers, sequenced using Thermo Sequenase pre-mixed cycle sequencing kits (GE Healthcare, UK), and analyzed using an SQ-5500E DNA sequencer (Hitachi Electronics). Two site-specific primers were designed from the sequence between the tail and SSR sequences. The primers designed from farther and nearer regions to SSR sequence were designated as SP1 and SP2, respectively. For the DNA fragment containing a compound SSR sequence at one end, only one site-specific primer (SP) was designed from the sequence flanking it. The primer pair comprising the site-specific primer (SP) and the compound SSR primer $(\mathrm{AG})_{6}(\mathrm{AC})_{3}$ was used as a compound SSR marker (Wu et al. 2008). 
Table 1 The nucleotide sequences of primers based on Reddy et al. (2008)

\begin{tabular}{lll}
\hline & Primer name & Primer sequence $\left(5^{\prime} \rightarrow 3^{\prime}\right)$ \\
\hline Random tailed primer & Ad1 & GTGAGCGCGCGTAATACGACTCACTATAGGGNNNNATGC \\
& Ad2 & GTGAGCGCGCGTAATACGACTCACTATAGGGNNNNGATC \\
& Ad3 & GTGAGCGCGCGTAATACGACTCACTATAGGGNNNNTAGC \\
& Ad4 & GTGAGCGCGCGTAATACGACTCACTATAGGGNNNNCTAG \\
Tail primer & Ad-P1 & GTGAGCGCGCGTAATACGA \\
& Ad-P2 & GTAATACGACTCACTATAGGG \\
\hline
\end{tabular}

The second-step walking contained a nested PCR using the above PCR kit. After the primary PCR with the tail primer Ad-P1 and a site-specific primer SP1, nested PCR was carried out using $1 \mu \mathrm{l}$ of 100 -fold diluted primary PCR products as template with a primer pair of another tail primer, Ad-P2 (Table 1), which was designed from $3^{\prime}$-flanking sequence of Ad-P1, and another site-specific primer SP2. Cloning and sequencing of the PCR fragments were carried out as mentioned above. A locus-specific primer (SP3) was newly designed between Ad-P2 and the SSR. The primer pair SP1/SP3 or SP2/SP3 was used as an SSR marker.

To characterize isolated SSR markers, leaves of $E$. polyandra were collected from 20 individuals distributed in the reverside of Yotagiri River and Otagiri River in Nagano-Prefecture. The leaves were dried and preserved at room temperature by packing with silica gel in plastic bags until used for DNA extraction. DNA was extracted from dried leaves by the CTAB method. The extracted DNA pellet was resuspended in $200 \mu \mathrm{l}$ of TE buffer and stored at $-20^{\circ} \mathrm{C}$. To amplify the SSR markers composed of a locus specific primer pair (Ep01-Ep11), an economic tail method for the amplification of fluorescent-labeled PCR fragments (Schuelke 2000) was adopted. The PCR amplification of SSR markers was carried out using the BioTaq $^{\text {TM }}$ PCR kit in a 5- $\mu \mathrm{l}$ reaction mixture containing $0.4 \mu \mathrm{M}$ of the forward primer (SP1 or SP2), $0.04 \mu \mathrm{M}$ reverse primer with a tail of M13f and $0.4 \mu \mathrm{M}$ of M13f primer of which one tenth $(0.04 \mu \mathrm{M})$ was $5^{\prime}$-labeled with Texas Red (Greiner BioOne). PCR amplification of compound SSR marker (Ep12) contained $0.4 \mu \mathrm{M}$ of the forward primer (SP) and $0.4 \mu \mathrm{M}$ of the compound SSR primer $(\mathrm{AG})_{6}(\mathrm{AC})_{3}$ of which one tenth $(0.04 \mu \mathrm{M})$ was $5^{\prime}$-labeled with Texas Red. After PCR amplification, DNA samples were denatured by heating at $94^{\circ} \mathrm{C}$ for $5 \mathrm{~min}$ and separated using the DNA Sequencer on a 6\% Long Ranger sequencing gel (FMC Bio-Products). The allele sizes were estimated using Fraglys version 3 (Hitachi Electronics Engineering). The observed and expected heterozygosity and the linkage disequilibrium at each SSR locus were calculated using ARLEQUIN version 2.0 software (Schneider et al. 2000).

In total, twelve polymorphic, codominant SSR markers, including a compound one, were isolated successfully (Table 2). There were two to 11 alleles per locus, and the observed and expected heterozygosities ranged from 0.05 to 0.90 and from 0.233 to 0.883 , respectively. With the exception of Ep01, 03, 05, 06 and 09, the observed heterozygosities of all other loci were consistent with expected ones after Bonferroni correction $(P<0.05, n=20$ individuals). Locus Ep03 showed significant linkage disequilibrium with locus Ep05 $(P<0.05)$. The random tailed genome-walking method using Phi29 DNA polymerase was shown to be effective to develop SSR or compound SSR markers. The method requires no large amounts of sample DNA because the sample DNA is directly amplified by Phi29 DNA polymerase.

Acknowledgment This work was supported by grants from the 21 st Century COE Program of MEXT, and a Grant-in-Aid for Scientific Research (No. 16101008) from JSPS, Japan.

\section{References}

Reddy PS, Mahanty S, Kaul T, Nair S, Sopory SK, Reddy MK (2008) A high-throughput genome-walking method and its use for cloning unknown flanking sequences. Anal Biochem 381:248-253

Schneider S, Roessli D, Excoffier L (2000) Arlequin, version 2.000: a software for population genetics data analysis. Genetics and Biometry Laboratory. University of Geneva, Geneva, Switzerland

Schuelke M (2000) An economic method for the fluorescent labeling of PCR fragments - a poor man's approach to genotyping for research and high-throughput diagnostics. Nat Biotechnol $18: 233-234$

Wu BY, Shiokawa A, Matsushita N, Hogetsu T (2008) Isolation of compound microsatellite loci in the herbaceous perennial Cirsium purpuratum (Maxim.) Matsum. Mol Ecol Resour 8: 814-817

Zhou Z, Miwa M, Hogetsu T (1999) Analysis of genetic structure of a Suillus grevillei population in a Larix keampferi stand by polymorphism of inter-simple sequence repeat (ISSR). New Phytol 144:55-63 


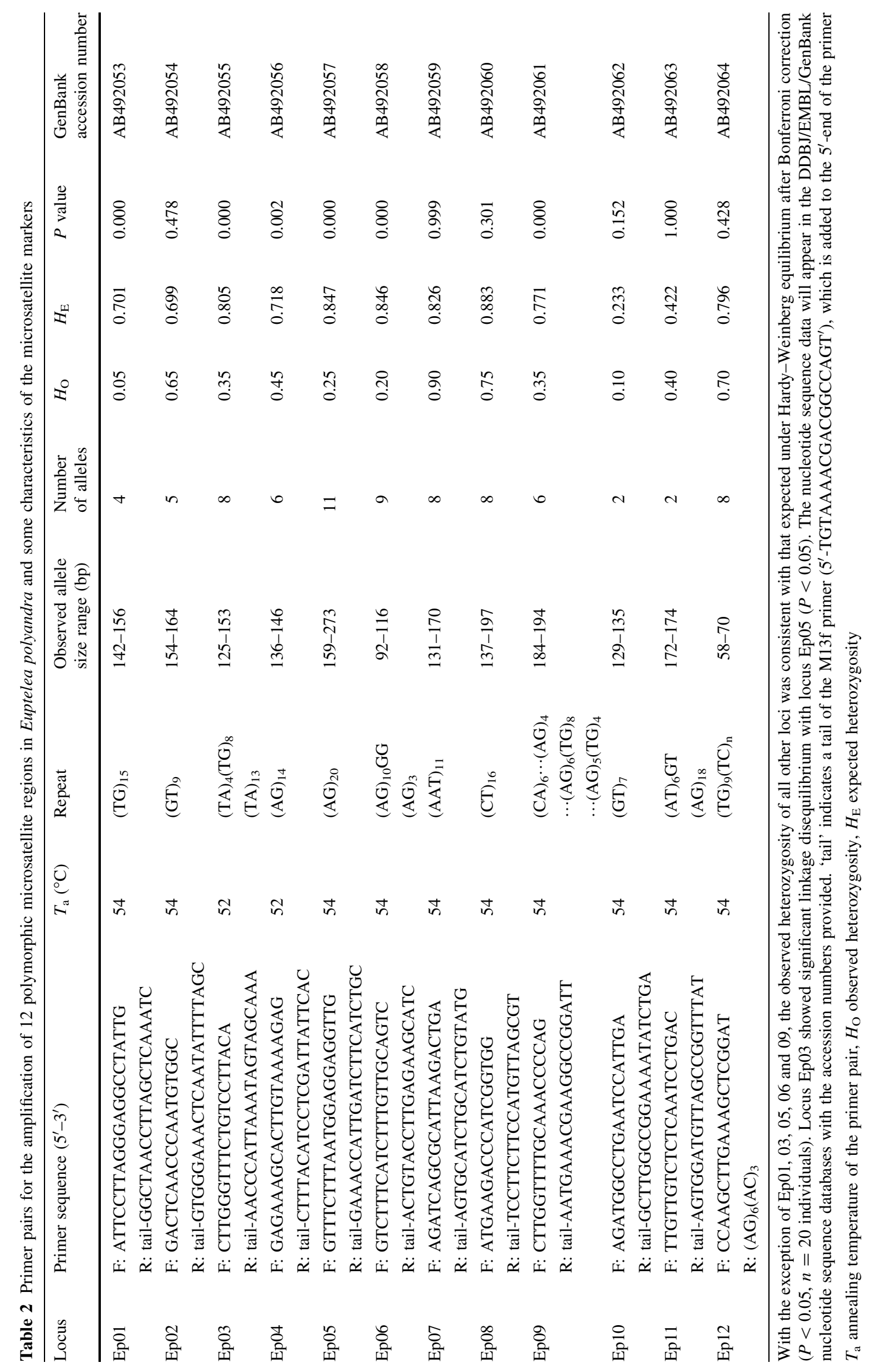

